\title{
Standardization of isothermal microcalorimetry in urinary tract infection detection by using artificial urine
}

\author{
Gernot Bonkat - Olivier Braissant • Malte Rieken - Anna Solokhina • \\ Andreas F. Widmer · Reno Frei - Andre van der Merwe - Stephen Wyler • \\ Thomas C. Gasser • Alexander Bachmann
}

Received: 30 March 2012 / Accepted: 12 July 2012 / Published online: 26 July 2012

(C) Springer-Verlag 2012

\begin{abstract}
Purpose Isothermal microcalorimetry (IMC) has recently been reported as a new method to rapidly detect urinary tract pathogens (UTP). However, further application of microcalorimetry in the clinical setting requires a standardized procedure. An important step toward such standardization is to use a reproducible growth medium. In this study, we investigated the potential of artificial urine in combination with microcalorimetry for detection of common UTP.

Methods A microcalorimeter equipped with 48 channels was used. Detection was accomplished, and growth was monitored for four bacterial strains in artificial urine at $37{ }^{\circ} \mathrm{C}$ by measuring metabolic heat flow $(\mu \mathrm{W}=\mu \mathrm{J} / \mathrm{s})$ as a
\end{abstract}

G. Bonkat $(\square) \cdot$ O. Braissant · M. Rieken · S. Wyler ·

T. C. Gasser · A. Bachmann

Department of Urology, University Hospital Basel,

Spitalstrasse 21, 4031 Basel, Switzerland

e-mail: bonkatg@uhbs.ch

G. Bonkat · O. Braissant · A. Solokhina

Laboratory of Biomechanics and Biocalorimetry (LOB2),

Faculty of Medicine, University of Basel,

c/o Biozentrum-Pharmazentrum, Klingelbergstrasse 50-70,

4056 Basel, Switzerland

\section{A. F. Widmer}

Division of Infectious Diseases and Hospital Epidemiology, University Hospital Basel, Petersgraben 4,

4031 Basel, Switzerland

R. Frei

Clinical Microbiology Laboratory, University Hospital Basel, Spitalstrasse 21, 4031 Basel, Switzerland

A. van der Merwe

Department of Urology, Faculty of Health Sciences, University of Stellenbosch, PO Box 19063, Tygerberg 7505, South Africa function of time. The strains were Escherichia coli, Proteus mirabilis, Enterococcus faecalis, and Staphylococcus aureus.

Result Bacterial growth was detected after 3-32 $\mathrm{h}$ with decreasing inoculums down to $1 \mathrm{CFU}$. The gram-negative strains grew and were detected faster than their grampositive counterparts. The growth rates the different strains were $0.75 \pm 0.11$ for E. coli, $0.74 \pm 0.10$ for E. faecalis, $1.31 \pm 0.04$ for P. mirabilis, and $0.56 \pm 0.20$ for $S$. aureus. The shape of individual heat flow curves was characteristic for each species independent of its initial concentration.

Conclusions IMC allows rapid detection of UTP in artificial urine. Clearly, different heat flow patterns enable accurate pathogen differentiation. UTP detection after only $4 \mathrm{~h}$ is realistic. The rapid detection of UTP tested in standardized artificial urine proves the diagnostic potential of IMC and warrants further microcalorimetric studies in the clinical setting of urinary tract infections.

Keywords Artificial urine - Diagnosis of urinary tract infection · Isothermal microcalorimetry $\cdot$ Heat flow curves Urinary tract infection

\section{Introduction}

Urinary tract infections (UTI) are among the most common bacterial infections in humans and account for significant morbidity and health care expenditures worldwide [1-3]. Pretreatment urine cultures are performed to confirm the diagnosis of UTI and to provide antimicrobial susceptibility patterns of pathogens involved. Although generally not required in cases of acute, uncomplicated cystitis [4], urine culture is still considered as standard of care in 
pyelonephritis, pregnant women, and men. Not surprisingly, urine cultures are among the most frequent culture analyses performed in the clinical microbiology laboratory [5]. However, up to $80 \%$ of urine samples are negative, resulting in considerable workload and consumption of resources [6]. Therefore, a rapid and cost-efficient assessment of UTI is still needed. In this context, isothermal microcalorimetry (IMC) has recently been proven to offer the potential to rapidly detect urinary tract pathogens (UTP) in urine [7]. In this proof-of-concept study, detection of bacterial growth was monitored in filtered sterilized urine from a healthy donor. However, further clinical application of microcalorimetry in UTI diagnosis requires a standardized procedure as urine composition could vary between individuals and also fluctuates in time within the same person [8, 9]. Pathologic conditions also might strongly modify urine composition, respectively [10]. An important step in such a standardization is the use of a reproducible growth medium dedicated to UTP. Artificial urine formulations might be such a valuable medium, since they have a reproducible composition and allow growth of the most common UTP [11]. In this study, we combined the use of artificial urine with microcalorimetry to improve and standardize detection of UTP by IMC.

\section{Materials and methods}

\section{Microorganisms}

Escherichia coli (DSM 10142), Enterococcus faecalis (JH2-2), Proteus mirabilis (DSM 4479), and Staphylococcus aureus (ATCC 25923) overnight cultures prepared in brain heart infusion (BHI-beef heart (infusion from $250 \mathrm{~g}$ ) $5.0 \mathrm{~g} \mathrm{~L}^{-1}$, calf brains (infusion from $200 \mathrm{~g}$ ) $12.5 \mathrm{~g} \mathrm{~L}^{-1}, \mathrm{Na}_{2} \mathrm{HPO}_{4} 2.5 \mathrm{~g} \mathrm{~L}^{-1}, \mathrm{D}(+)$-glucose $2.0 \mathrm{~g} \mathrm{~L}^{-1}$, peptone $10.0 \mathrm{~g} \mathrm{~L}^{-1}$, $\mathrm{NaCl} 5.0 \mathrm{~g} \mathrm{~L}^{-1}$ ) were diluted in sterile saline $(0.85 \% \mathrm{NaCl})$ and adjusted to an optical density $\left(\mathrm{OD}_{600}\right)$ of ca. 0.132 ( $\sim 0.5$ McFarland). From this suspension, serial tenfold dilutions were prepared in sterile saline to attain concentrations of ca. $10^{5}, 10^{3}, 10^{1}$, and $1 \mathrm{CFU} / \mathrm{mL}$. The inoculums concentrations were confirmed by cultures on BHI agar plates.

\section{Artificial urine}

Artificial urine was prepared according to the formulation provided in Brooks and Keevil [11]: peptone $1.0 \mathrm{~g} \mathrm{~L}^{-1}$, yeast extract $5.0 \mathrm{mg} \mathrm{L}^{-1}$, lactic acid $0.1 \mathrm{~g} \mathrm{~L}^{-1}$, citric acid $0.4 \mathrm{~g} \mathrm{~L}^{-1}, \mathrm{NaHCO}_{3} 2.1 \mathrm{~g} \mathrm{~L}^{-1}$, urea $10.0 \mathrm{~g} \mathrm{~L}^{-1}$, uric acid $0.1 \mathrm{~g} \mathrm{~L}^{-1}$, creatinine $70.0 \mathrm{mg} \mathrm{L}{ }^{-1}, \mathrm{CaCl}_{2} \cdot 2 \mathrm{H}_{2} \mathrm{O} 0.37 \mathrm{~g} \mathrm{~L}^{-1}$, $\mathrm{NaCl} 5.2 \mathrm{~g} \mathrm{~L}^{-1}, \mathrm{FeSO}_{4} \cdot 7 \mathrm{H}_{2} \mathrm{O} 10.0 \mathrm{mg} \mathrm{L}^{-1}, \mathrm{MgSO}_{4} \cdot 7 \mathrm{H}_{2} \mathrm{O}$ $0.5 \mathrm{~g} \mathrm{~L}^{-1}, \mathrm{NaSO}_{4} \cdot 10 \mathrm{H}_{2} \mathrm{O} 3.2 \mathrm{~g} \mathrm{~L}^{-1}, \mathrm{~K}_{2} \mathrm{HPO}_{4} 1.2 \mathrm{~g} \mathrm{~L}^{-1}$,
$\mathrm{KH}_{2} \mathrm{PO}_{4} 1.0 \mathrm{~g} \mathrm{~L}^{-1}, \mathrm{NH}_{4} \mathrm{C} 11.3 \mathrm{~g} \mathrm{~L}^{-1}$. To enhance pathogens growth and thus detection, we added $20 \mathrm{mg} \mathrm{L}^{-1}$ of glucose, $20 \mathrm{mg} \mathrm{L}^{-1}$ of lactose, and $20 \mathrm{mg} \mathrm{L}^{-1}$ of saccharose to the artificial urine. This range corresponds to what can be detected in healthy patient urine [12].

\section{Microcalorimetry}

A microcalorimetry instrument (TAM48, TA Instruments, New Castle, DE) was used to measure the heat flow during the growth of the different strains in artificial urine at $37^{\circ} \mathrm{C}$. Four-milliliter ampoules were filed with $2.9 \mathrm{ml}$ of artificial urine, and $100 \mu \mathrm{l}$ of inoculums was added. The microcalorimetric ampoules were then inserted into the measuring channels, and heat flows were recorded until the signal returned to baseline or up to a maximum of 5 days.

Calorimetric detection of microorganisms and estimation of growth rates

Detection time was defined as the time to reach a rising heat flow rate signal of $10 \mu \mathrm{W}$ (40 times the sensitivity of the calorimeters). Growth rate was calculated using an exponential model $\left(\mathrm{Qt}=\mathrm{Q}_{0} \cdot \mathrm{e}^{\mu \mathrm{t}}\right.$, where $\mathrm{Q}$ represents the heat-i.e., the integral of the heat flow curve) over the exponential part of the curve. Generation time was obtained using the relation $\operatorname{tg}=\ln 2 / \mu$, where $\mu$ is the growth rate obtained previously. Data analysis was accomplished with the manufacturer's software (TAM Assistant) and the R Statistical package [R Development Core Team 2008].

\section{Results}

Detection times are summarized in Table 1, and growth parameters in artificial urine are summarized in Table 2. Detection was rapidly achieved for all different bacterial species tested. The gram-negative bacteria grew and were detected faster than their gram-positive counterparts. $P$. mirabilis and E. coli were detected in less than $4 \mathrm{~h}$ for highest inoculum concentration and less than $10 \mathrm{~h}$ for concentration of $1 \mathrm{CFU} / \mathrm{mL}$. The growth rates for $P$. mirabilis and E. coli were $1.31 \pm 0.04$ and $0.75 \pm 0.11$, respectively. Similarly, $S$. aureus was also detected in less than $4 \mathrm{~h}$ for highest inoculum concentration but required ca. $20 \mathrm{~h}$ to be detected when a concentration of $10 \mathrm{CFU} / \mathrm{mL}$ was used, and was not detected for concentration down to $1 \mathrm{CFU} / \mathrm{ml}$. This can be easily explained because $S$. aureus has the slowest growth rate observed in urine $(0.56 \pm 0.20)$. Finally, E. faecalis was detected within $10 \mathrm{~h}$ for the highest inoculums and $32 \mathrm{~h}$ when a concentration of $1 \mathrm{CFU} / \mathrm{mL}$ was used. The growth rate for 
Table 1 Detection time in hours achieved for the different pathogens tested at various inoculum concentrations

\begin{tabular}{|c|c|c|c|c|}
\hline \multirow[t]{2}{*}{ Microorganism } & \multicolumn{4}{|c|}{ Inoculum concentration $(\mathrm{CFU} / \mathrm{mL})$} \\
\hline & $10^{5}$ & $10^{3}$ & $10^{1}$ & $10^{\circ}$ \\
\hline E. coli & $3.66 \pm 0.09$ & $6.30 \pm 0.05$ & $9.38 \pm 0.77$ & $9.33^{\mathrm{a}}$ \\
\hline E. faecalis & $9.16 \pm 0.98$ & $12.25 \pm 0.74$ & $16.22 \pm 0.24$ & $32.25^{\mathrm{a}}$ \\
\hline P. mirabilis & $3.33 \pm 0.01$ & $6.39 \pm 0.17$ & $9.75 \pm 0.41$ & ND \\
\hline S. aureus & $3.94 \pm 0.34$ & $9.11 \pm 0.82$ & $20.45 \pm 1.00$ & ND \\
\hline
\end{tabular}

Measured microbial concentrations at targeted concentrations of $10^{5} \mathrm{CFU} / \mathrm{mL}$ were $1.12 \times 10^{5} \mathrm{CFU} / \mathrm{mL}$ for E. coli, $1.71 \times 10^{5} \mathrm{CFU} / \mathrm{mL}$ for E. faecalis, $1.41 \times 10^{5} \mathrm{CFU} / \mathrm{mL}$ for $P$. mirabilis, and $0.81 \times 10^{5} \mathrm{CFU} / \mathrm{mL}$ for $S$. aureus

ND not detectable

${ }^{a}$ Less than three replicate heat flow curves were obtained; no standard deviation is indicated

Table 2 Growth parameter [growth rate $(\mu)$ and generation time $(\operatorname{tg})$ ] determined using microcalorimetry data for all dilutions of a microorganism and comparison with available literature data

\begin{tabular}{llllll}
\hline Microorganism & $\mu(\mathrm{AUM})\left[\mathrm{h}^{-1}\right]$ & $\operatorname{tg}(\mathrm{AUM})[\mathrm{h}]$ & $n$ & $\operatorname{tg}($ literature) $[\mathrm{h}]$ & References \\
\hline E. coli & $0.75 \pm 0.11$ & $0.94 \pm 0.13$ & 11 & $0.75-1.67$ & Roos et al. [24] \\
E. faecalis & $0.74 \pm 0.10$ & $0.95 \pm 0.13$ & 11 & $0.81 \pm 0.05$ & Vebo et al. [25] \\
P. mirabilis & $1.31 \pm 0.04$ & $0.53 \pm 0.02$ & 9 & $0.40-1.02$ & Sosa et al. [26] \\
S. aureus & $0.56 \pm 0.20$ & $1.42 \pm 0.51$ & 9 & $1.41 \pm 0.21$ & Bonkat et al. [7] \\
\hline
\end{tabular}

AUM artificial urine medium

E. faecalis was $0.74 \pm 0.10$ and was similar to the growth rate of E. coli. However, in urine, E. faecalis seems to have a slightly longer lag phase. For $S$. aureus and $P$. mirabilis, the lowest dilution was not detected within the time frame investigated. Finally, the growth-related heat flow pattern of each bacterial species tested was clearly different. Strong differences in the pattern shape and peak intensity potentially allow pathogen identification (Fig. 1) as proposed in other studies [13, 14].

\section{Discussion}

Urinary tract infection (UTI) is among the most common infectious diseases diagnosed in the clinical microbiology laboratory. However, the majority of urine samples sent to the laboratory are negative. Screening methods (e.g., dip stick testing, automated urine flow cytometry, microscopy) for UTI are limited [15-17]. In addition, these tests are not being able to replace urine cultures because they neither identify the causal pathogen nor establish antibiotic susceptibility-guided antibiotic treatment. The diagnostic gold standard, urine culture, is limited in itself by the typical delay of 2-3 days to deliver results and drug susceptibility patterns. Therefore, there is still a significant interest in developing rapid diagnostics for UTI. In this context, we could recently demonstrate that isothermal microcalorimetry (IMC) offers to be such a promising approach [7]. IMC measures heat production rates of physical, chemical, or biological processes and offers several advantages. Its high sensitivity in the order of $0.2 \mu \mathrm{W}$ allows detection of $10^{2}$ active microorganisms per sample. This is even more important as studies comparing voided urine specimens and bladder aspirate specimens in women with UTI have shown that the traditional criterion for a positive culture of voided urine $\left(10^{5} \mathrm{CFU} / \mathrm{mL}\right)$ is insensitive for cystitis, and 30-50\% of women with bladder infection have colony counts of $10^{2}-10^{4} \mathrm{CFU} / \mathrm{mL}$ in voided urine [18], a range that is mostly covered by IMC. In our present study conditions (i.e., artificial urine), the high sensitivity of isothermal microcalorimetry (IMC) allowed the rapid detection of all urinary tract pathogens (UTP) investigated. In addition, the use of artificial urine of defined composition allows standardizing the results and thus in turn will also allow comparisons between bacterial strains pathogenicity. For example, Gordon and Riley [19] suggested that E. coli strains isolated from the urinary tract have significantly higher in vitro growth rates in urine compared with strains isolated from other areas. Thus, based on their growth rate determined by IMC, it seems possible to assess the pathogenicity of different strains. For this purpose, it must be noted that (1) growth rate measured in this study is consistent with growth rate measured in filter-sterilized urine (Table 2) and (2) very small differences have been observed when comparing microcalorimetric data obtained in real urine and those in artificial urine [7]. In contrast to the previous study performed in filter-sterilized urine from a healthy donor, 

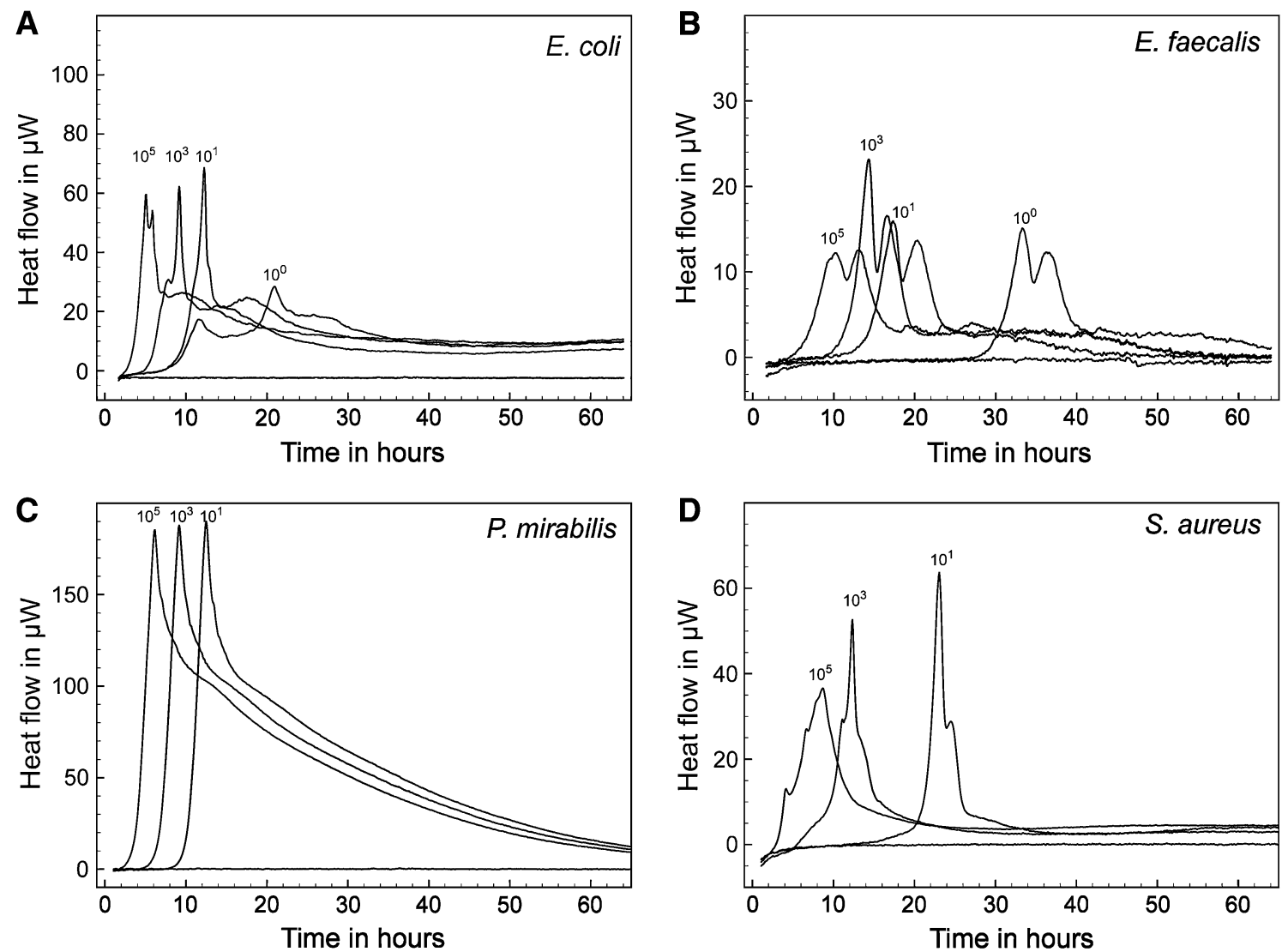

Fig. 1 Representative heat flow curves of urinary tract pathogens in artificial urine. Growth-related heat flow curves of serial dilutions of the four urinary pathogens investigated: a E. coli; b E. faecalis; c P. mirabilis; d S. aureus

growth rate was slightly higher (4-16\%), resulting in shorter generation time. This higher growth rate is likely explained by the presence of small amount of sugars in the artificial urine formulation used in our study. In addition, the absence of natural antimicrobial molecules such as antimicrobial peptides [20] commonly found in urine from our artificial urine is also likely to promote a faster growth of microorganisms tested. Another benefit of using artificial urine is the possibility to achieve identification of the pathogens involved. It is commonly admitted that a particular bacterium in a defined medium will produce a specific heat flow pattern. However, although bacterial identifications using microcalorimetry have already been proposed in the 1970s [21], it was also emphasized that environmental conditions influenced the heat flow pattern and might compromise such identification [22]. In this context, artificial urine provides the stable environmental conditions necessary to obtain reproducible heat flow patterns and allows identification. The identification process itself (i.e., the assignation of a genus or species name to an unknown heat flow pattern) can be performed by various means including cross-correlation analysis [14], discriminant analysis [13], and support vector machines
[23]. Note that all these methods focus on the pattern identification and not on parameters such as growth rate, detection time, or any other. Increasing performance of computer since the 1970s has allowed performing such analyses in a few seconds to minutes nowadays. For example, in their paper, Lopez and colleagues could achieve identification with an accuracy of ca. $100 \%$ using single strains only [14]. The major difficulty we have to be concerned with might be polymicrobial growth. However, knowledge of growth-related heat flow patterns in individual species might allow splitting the contribution of several (up to 3) pathogens using deconvolution algorithm. Similarly, slightly different heat flow pattern has been observed for methicillin-resistant $S$. aureus and for methicillin-susceptible $S$. aureus [24]. Therefore, use of pattern recognition algorithm should be used with care, and knowledge of heat flow pattern should be based on a rather large number of strains belonging to a single species and including resistant and susceptible strains to catch the "natural variation" within the considered species. Considering all these elements, we believe that further studies will allow IMC to be used in the field of UTI diagnosis or even exclusion. 


\section{Conclusions}

IMC allows rapid detection of UTP in artificial urine. Clearly, different heat flow patterns enable accurate pathogen differentiation. The rapid detection of UTP tested in standardized artificial urine proves the potential of IMC and warrants further studies in the setting of urinary tract infections. Especially, clinical strains obtained during routine microbiological investigations should be investigated to further validate this approach.

Conflict of interest None of the contributing authors have any conflict of interest relevant to the subject matter or materials discussed in the manuscript. No funding or other financial support was received

\section{References}

1. Keating KN, Perfetto EM, Subedi P (2005) Economic burden of uncomplicated urinary tract infections: direct, indirect and intangible costs. Expert Rev Pharmacoecon Outcomes Res 5:457-466

2. Wilson ML, Gaido L (2004) Laboratory diagnosis of urinary tract infections in adult patients. Clin Infect Dis 38:1150-1158

3. Raynor MC, Carson CC III (2011) Urinary infections in men. Med Clin N Am 95:43-54

4. Hooton TM (2012) Clinical practice. Uncomplicated urinary tract infection. N Engl J Med 366:1028-1037

5. Brilha S, Proenca H, Cristino JM, Hanscheid T (2010) Use of flow cytometry (Sysmex) UF-100) to screen for positive urine cultures: in search for the ideal cut-off. Clin Chem Lab Med 48:289-292

6. Okada H, Sakai Y, Miyazaki S, Arakawa S, Hamaguchi Y, Kamidono S (2000) Detection of significant bacteriuria by automated urinalysis using flow cytometry. J Clin Microbiol 38:2870-2872

7. Bonkat G, Braissant $\mathrm{O}$, Widmer AF, Frei R, Rieken M, Wyler S, Gasser TC, Wirz D, Daniels AU, Bachmann A (2012) Rapid detection of urinary tract pathogens using microcalorimetry: principle, technique and first results. BJU Int. doi:10.1111/j. 1464-410X.2011.10902.x.

8. Hesse A, Classen A, Knoll M, Timmermann F, Vahlensieck W (1986) Dependence of urine composition on the age and sex of healthy subjects. Clin Chim Acta 160:79-86

9. Taylor EN, Curhan GC (2007) Differences in 24-hour urine composition between black and white women. J Am Soc Nephrol 18:654-659

10. Eisner BH, Eisenberg ML, Stoller ML (2010) Relationship between body mass index and quantitative 24-hour urine chemistries in patients with nephrolithiasis. Urology 75:1289-1293
11. Brooks T, Keevil CW (1997) A simple artificial urine for the growth of urinary pathogens. Lett Appl Microbiol 24:203-206

12. Young DS, Jackson AJ (1970) Thin-layer chromatography of urinary carbohydrates. A comparative evaluation of procedures. Clin Chem 16:954-959

13. Bermudez J, Lopez D, Sanahuja A, Vinas M, Loren JG (1988) Discriminant analysis of microcalorimetric data of bacterial growth. Can J Microbiol 34:1058-1062

14. Lopez D, Vinas M, Loren JG, Bermudez J (1987) Analysis of microcalorimetric curves for bacterial identification. Can J Microbiol 33:6-11

15. Pieretti B, Brunati P, Pini B, Colzani C, Congedo P, Rocchi M, Terramocci R (2010) Bacteriuria and leukocyturia: the role of automated flow cytometry compared with urine culture. J Clin Microbiol 48(11):3990-3996

16. St John A, Boyd JC, Lowes AJ, Price CP (2006) The use of urinary dipstick tests to exclude urinary tract infection: a systematic review of the literature. Am J Clin Pathol 126:428-436

17. Williams GJ, Macaskill P, Chan SF, Turner RM, Hodson E, Craig JC (2010) Absolute and relative accuracy of rapid urine tests for urinary tract infection in children: a meta-analysis. Lancet Infect Dis 10:240-250

18. Stamm WE, Counts GW, Running KR, Fihn S, Turck M, Holmes KK (1982) Diagnosis of coliform infection in acutely dysuric women. N Engl J Med 307:463-468

19. Gordon DM, Riley MA (1992) A theoretical and experimental analysis of bacterial growth in the bladder. Mol Microbiol 6:555-562

20. Ali AS, Townes CL, Hall J, Pickard RS (2009) Maintaining a sterile urinary tract: the role of antimicrobial peptides. J Urol 182:21-28

21. Boling EA, Blanchard GC, Russell WJ (1973) Bacterial identification by microcalorimetry. Nature 241:472-473

22. Bunker JC, James AM (1986) Microcalorimetric studies on the effects of media and environmental conditions on the growth of bacteria. Microbios 47:177-188

23. Christianini N, Shawe-Taylor J (2000) Introduction to support vector machines and other kernel-based learning methods. Cambridge University Press, Cambridge, pp 93-122

24. von Ah U, Wirz D, Daniels AU (2008) Rapid differentiation of methicillin-susceptible Staphylococcus aureus from methicillinresistant $S$. aureus and MIC determinations by isothermal microcalorimetry. J Clin Microbiol 46:2083-2087

25. Vebo HC, Solheim M, Snipen L, Nes IF, Brede DA (2010) Comparative genomic analysis of pathogenic and probiotic Enterococcus faecalis isolates, and their transcriptional responses to growth in human urine. PLoS One 5:e12489

26. Sosa V, Schlapp G, Zunino P (2006) Proteus mirabilis isolates of different origins do not show correlation with virulence attributes and can colonize the urinary tract of mice. Microbiol 152: 2149-2157 